\title{
A Cross-Sectional Design: Marital Satisfaction of Mather and Self-Esteem in Children
}

\author{
Mohammad Hosein Saket ${ }^{1 *}$
}

\section{ABSTRACT}

Introduction: One of the important discussions in the family is the quality of the relationship between the parents. Objective: The presented study was conducted with aim to determine the relation between marital Satisfactions of mother with Self-esteem in children. Method: The present study, with a causal-comparative framework and in descriptive domain of studies. The target formed the population included all female students living in Tehran. To this aim, 85 ( $\mathrm{N}=85$ ) Students were selected by Purposive sampling method. Data collection was used on survey methods to assess index of marital satisfaction and self-esteem questionnaire. Data collected were used with the help of Pearson correlation test and regression analysis. Results: Data analysis showed that amount of marital satisfaction with self- esteem of children is significant. In this regard, marital satisfaction of mothers was determined by Selfesteem ( $r=0.24, \mathrm{p}<0.05)$. Conclusion: As the findings offer preventive implications that could be important in the area of applications.

Keywords: Marital Satisfaction, Self-Esteem, Children

One of the important discussions in the family is the quality of the relationship between the parents. Marital adjustment affects many aspects of people's individual and social life. Several evidences show that parents of children with mental or physical problems are more likely to have emotional problems, limiting economic and social nature often with devastating and pervasive encounters, (Khamis, 2007). Although all family members and their functions in such a situation are damaged (Hearing et al., 2006) due to the traditional role of mothers 'Watchmen', they assume more responsibilities for their children which as a result, they encounter more psychological problems. Assumption which is based On is That Difficulties Related To Care From Son problematic, Parents and Specially leaves Mothers Exposed to the dangers Related To Mental Health which affect children and his performance (Olson and Huang, 2001; McConkey et al, 2007). Mother is the First Person That Establishes Straight Relationship with the Children.

\footnotetext{
${ }^{1}$ Conventional Master, University of Applied Science, Tehran, Iran

*Responding Author

(c) 2016 I M Saket; licensee IJIP. This is an Open Access Research distributed under the terms of the Creative Commons Attribution License (http://creativecommons.org/licenses/by/2.0), which permits unrestricted use, distribution, and reproduction in any Medium, provided the original work is properly cited.
} 


\section{A Cross-Sectional Design: Marital Satisfaction of Mather and Self-Esteem in Children}

Problems that Mothers face With Children , the Children need for Ongoing care, The importance of Building the Special conditions for Growth, Parents experience tension due to lack of skills, behaviors of children self-care in this group of Children, Are all the grounds to provide weakness to a normally functioned mother. Existence of such problems will have an increase in average non marital satisfaction of the mothers of disabled children compared with mothers of normal children. Also, the expectations away from the ability of children and in its wake not meeting the expectations cause the failure of parents (Hind, 2004; quoted mehrabi, 1383). In total, these conditions can cause stress in the field of child development, lack of interest in relation to the environment, a sense of low self-esteem and mother's worthlessness and negative consequences such as low self-efficacy, anxiety, aggression (Narimani et al, 2007), low self-esteem and severe depression (lajevardi, 1371) to be followed in children's and their health risks (Mohammadi, Dadkhah, 1381). Efficacy of social cognitive theory, Albert Bandura (1997) is derived that beliefs or judgments of a person refers to his or her abilities to perform the duties and responsibilities (Karadenas, 2007; quoted Maher, 1386). Knowledge and understanding of their individual capabilities is known as efficacy. This concept have been studied for nearly three decades by psychologists and theorists (Harington and Olson, 2005; quoted Saif al, 1385).refers To feel self-esteem, self worth, a sense of efficacy in dealing with life (Bandura, 1997; quoted Seif et al, 1380). , At the age of eight children in his own descriptions is less objective and is more focused on psychological aspects. ) and often compare themselves to others and thus lay the foundations of self-efficacy in children (Harington, 2000; Toozandehjani and Kamalipour translation, 1380) Self-efficacy is the result of the interaction of organism and environment. It can be said simply believing one's self features include: needs, motivations, attitudes, abilities, knowledge and understanding that forms behavior patterns (Amini, 1375). Most sociologists and psychologists have mentioned that some positive self-concept to be synonymous with high selfefficacy and some self-esteem to be synonymous with efficacy (Marchty, 2002, quoted by gohari, 1377). Research has shown that, there is a relation between parents, parenting styles and self-efficacy (crown, 1996; Moore, 1998; quoted by Fathi ashtiani, 1378). National self efficacy, is now one of the distinguishing factors of advanced and backward nations. Studies have shown that human resource of advanced countries have high efficacy and hence trying to increase the features of long-term plans countries around the world And high-efficacy is directly related to marital satisfaction and parenting styles (Ross, 2002; quoted by Karim Zadeh,1380).

On the other hand parenting process refers with knowledge in every aspect of health, physical development, personality, mental, emotional, emotional, social, from infancy to adulthood (Isaacs, 1995; quoted by Rajayi, 1387). Parents who waver in their communication, lack of confidence and disagree with stability in the upbringing of their children, the parenting based on pattern of exclusion, extreme protection with negligible or control, dual discipline, moral standards emotional frailty using bulk their behavior in children neurotic the consolidation and dumped into the emotional and affective children in dire need and in such circumstances the sense of trust and security that the healthy emotional development of numerous fails (Berichery, 1998, quoted by Dehghanpoor and Khrazchi, 1377). On the other hand, Marriage satisfaction 


\section{A Cross-Sectional Design: Marital Satisfaction of Mather and Self-Esteem in Children}

refers to feel Happiness, Satisfaction And Pleasure By Female Or Husband when they consider All Aspects Of Marriage, (Hawkins, 2003; quoted by Sana'i, 1378). By definition, a couple's marital satisfaction is defined in the dictionary as a performance and appropriate behavior based on traditional tasks, customary law for each of them in family (danaee, 1391). Also, Ellis (1989) States that marital satisfaction and feeling of happiness, satisfaction, and joy experienced by the husband or wife when they consider all aspects of their marriage (Soleimanian, 1373). As mentioned, each Family has a Special Style in their children's Upbringing Under the Title of Parenting which is affected From different Factors like Cultural factors. most of the disorders and incompatibility of Children caused by attention deficit often is in this sensitive period (Hall, 2000; quoted by nejati 1379). Given the importance of these issues and concerns in regard to the application of prevention and treatment, aimed to study the relationship between mother's parenting stress and marital satisfaction, self-efficacy (related to parenting stress with the efficacy of students) and students with visual impairment and blindness.

\section{ETHICAL PRINCIPLES}

In this study, the informed consent was obtained without coercion, threat, enticement and seduction and their decision to refuse or accept to participate in the study were respected. It was also tried that the research methods do not contradict with the religious and cultural principles of the participants and the participants were respected in all stages of design, implementation and reporting in terms of human dignity, respect and protection of their physical and mental integrity so that conducting the research would not delay in the process of medical care for the participants.

\section{Statistical Analysis}

In the present study due to the nature of the study and previous research to examine the relation between three variables of marital satisfaction and self-esteem and according to the distance of the scale of all three parametric test, Pearson test and the significant relation were analyzed by ttest.

\section{METHOD}

The present research is correlation- descriptive one from cross sectional type which aimed to discuss relationship between martial satisfactions of Mather to self esteem in children. This study is a causal-comparative plan and solidarity in the field of descriptive design. The target formed a population included all 7-11 year-old female students living in Tehran. The presented study data were collected in a survey in 1394 during 25 June until 9 March, using questionnaires and clinical interviews. For this purpose Eighty-five $(\mathrm{N}=85)$ students were selected through Purposive sampling. The method of collecting data was survey and indicators to measure parenting stress, job satisfaction and self-efficacy questionnaire by Enrich and general selfefficacy were used. Data collected were used with Pearson correlation test, F-test and regression analysis. As well as qualitative data were analyzed obtained from the assessment coding demographic and qualitative data analysis tool ATLAS.ti -5.2. In the first stage with the kind 


\section{A Cross-Sectional Design: Marital Satisfaction of Mather and Self-Esteem in Children}

permission of the Department of Education and in coordination with the school administrators to inform parents and students of the overall objectives of the research, the questionnaire was available to parents and students. Then the parents and students were asked to carefully and fully complete the questionnaire. After completing questionnaires from parents and students in this study were appreciated.

\section{Instruments}

- Enrich paired Scale: This Likert questionnaire consists of 35 items that evaluate potential problematic areas and identify areas of strength used in the marital relationship. By David Olson and Amy Olson couple Enrich Inventory questionnaire in 2000 was conducted on 25,501 married couples. Alpha coefficients for subscales of marital satisfaction questionnaire, communication, conflict resolution, and idealistic distortion, respectively, 0.86, 0.80, 0.84, 0.83 and test-retest reliability for each subscale questionnaire in order $86 / 0,81 / 0,90 / 0,92 / 0$ reported. In this comfortable research comfortable alpha coefficient of the questionnaire (1389) with 365 couples, respectively 0.68 (with the removal of question 24 is an alpha 0.78 ), $0.78,0.62$ and 0.77 on the Came. Mirkheshti research in Iran (1375), Mahdavian (1376), Moradi (1380), Sanaee (1381), haghshenas (1383) have shown that the scale of Utrecht and Persian translations of validity and reliability is required.

- Self-esteem: Participants completed the California Self-Evaluation Scales (CSES; Phinney \& Gough, 1984). The CSES includes 20 items assessing four dimensions of self-esteem (sample item in par-entheses): global self-esteem, a global measure of self-regard (satisfaction with self); physical self-esteem , assessing participants' regard for their physical attractiveness (my physical self-image); social self-esteem, measuring participants' perceived impression on others (impression I have on others); intellectual self-esteem , assessing participants' regard for their intellectual abilities and potential for success (my potential for success). Each item is rated on a 9-point scale, with varying anchors depending on the attribute being rated. For all scales, $1=$ extremely low self-esteem on the attribute and 9=extremely high self-esteem on the attribute. With 20 items total, ${ }^{\circledR}$ ve items are standardized and summed to produce each of the four dimensions. I factor analyzed the 20 items for men and women separately, and then for men and women together, to determine whether the four factors emerged for this sample. For each factor analysis, the four factors emerged with only trivial misassignment of items to factors. 


\section{RESULTS}

Demographic features of the participants

Table1: Demographic status of the participants of the study

\begin{tabular}{|c|c|c|c|c|c|c|c|c|c|}
\hline 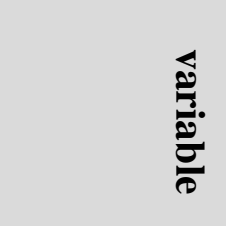 & & 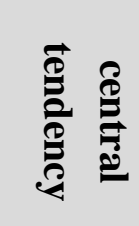 & & & 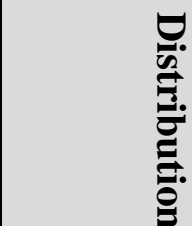 & & & 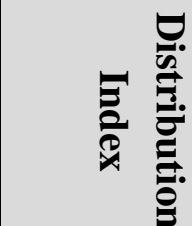 & \\
\hline & है & $\begin{array}{l}\text { 总 } \\
\text { : } \\
\text { : }\end{array}$ & 当 & & . & $g$ & $\begin{array}{l}n \\
\qquad \\
0 \\
0 \\
0 \\
\end{array}$ & 竎 & 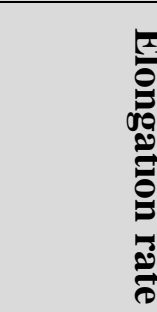 \\
\hline $\begin{array}{l}\text { marital } \\
\text { Satisfaction }\end{array}$ & 84 & 102 & 107 & 97 & 727.4 & 26.97 & 3.93 & 0.43 & -.88 \\
\hline Self-esteem & 120 & 116 & 109.6 & 131 & 900 & 30 & 4.16 & $\begin{array}{l}-0.79 \\
\end{array}$ & -0.003 \\
\hline $\begin{array}{l}\text { Academic } \\
\text { efficacy }\end{array}$ & 33 & 35 & 34.07 & 44 & 100.90 & 10.04 & 1.36 & -0.63 & -0.37 \\
\hline $\begin{array}{l}\text { Social } \\
\text { efficacy }\end{array}$ & 37 & 33 & 33.05 & 40 & 84.74 & 90.20 & 1.26 & -0.50 & -0.15 \\
\hline $\begin{array}{l}\text { Emotional } \\
\text { efficacy }\end{array}$ & 105 & 37 & 36.54 & 44 & 119.59 & 10.93 & 1.50 & -0.61 & -0.37 \\
\hline $\begin{array}{l}\text { marital } \\
\text { satisfaction }\end{array}$ & 105 & 107 & 108 & 46 & 62.10 & 7.88 & 1.12 & 0.4 & 2.02 \\
\hline
\end{tabular}

As seen in Table 1, statistical indicators is proposed, such as mean, median, standard deviation and the Elongation.

\section{Kolmogorov-Smirnov test}

As you are aware, one of the preconditions for the use of parametric tests, is normality of distribution in research variables, the Kolmogorov-Smirnov test was used to investigate the above preconditions that results is provided in Table 2 .

Table 2: results of Kolmogorov-Smirnov test

\begin{tabular}{|l|l|l|}
\hline Variable & $\mathbf{Z}$ & Sig. \\
\hline marital Satisfaction & 0.79 & 0.39 \\
\hline Self-esteem & 0.91 & 0.31 \\
\hline
\end{tabular}

According to the results in Table 2, it can be concluded that all variables studied were normal, as a result to evaluate the assumptions of the study parametric tests can be used. 
A Cross-Sectional Design: Marital Satisfaction of Mather and Self-Esteem in Children

Table 3: The correlation coefficient between marital satisfaction and self- esteem

\begin{tabular}{|l|l|l|l|l|l|}
\hline Variable & Correlation & Coefficient & Direction & $\mathbf{R}^{2}$ & Sig. \\
\hline $\begin{array}{l}\text { marital } \\
\text { satisfaction } \\
\text { and Self- } \\
\text { esteem }\end{array}$ & Pierson & 0.24 & positive & 0.07 & 0.05 \\
\hline
\end{tabular}

According to the table above and the obtained correlation (0.24) can be concluded that between marital satisfaction and Self-esteem.

\section{DISCUSSION}

After a study of the relationship between parenting stress and marital satisfaction of efficacy students with visual impairment and blindness was performed. The results showed that there is significant relation between parenting stress and marital satisfaction with self-efficacy of children. Between parenting stress of mothers with three levels of academic self-efficacy ( $\mathrm{r}=-$ 0.35), Social ( $\mathrm{r}=-0.27)$ And emotional $(\mathrm{r}=-0.28)$ A significant relationship exists. The results showed that the share of parenting stress in mothers define self-efficacy students more than the share of mother of marital satisfaction. There is also a significant inverse correlation observed between the two components of marital satisfaction and parenting stress.

Yaghob Khani (1372), mehrafroz (1381), Hosseini nesbat (1387), Kimberley (1386), Kimberley et al (2010) in their study concluded that there is significant relation and negative correlation in parenting stress with efficacy .In this regard valizadeh (1390) in his study je carried samples consisted of 304 students that aims to determine the role of self-esteem and self-concept of intermediary in the relationship between parenting styles and academic achievement that the direct effects of three permissive parenting styles, authoritarian and authoritative are significant academic achievement requirements. Yousefi (1386) in his study With the Title Relationship Style of parenting by parents With social Skills And Aspects From Self-concept Knowledge of High school Students, the results of his study suggests That Iranian Children that Belong To decisive Families completely lack less social skills. In another study yaghobkhani (1372) on the effects of family environment on children's achievement showed the warmth of family is positively correlated with academic achievement. Warm and more controlled Families showed more success. Johnston and Chen (2010) showed in their studies that the overall academic achievement of students with authoritarian parenting style have no negative relationship with the authoritarian style of communication (bitaraf, 1389). on the other hand Henriksen and Rocker (2000) have been shown in their research that styles of parenting, especially supportive parenting styles, led to the formation of children and adolescents , while the lack of support and the use of authoritarian methods leads to various problems such as substance abuse and dropout . Schunk (1996) in his study showed, positive academic motivation and academic achievement are linked with authoritative style. This style provides background which through it parents reinforce children's independence and individuality, they create opportunities for the family to decide on their participation. In several studies (Dornbusch et al, 1987; Lamborn et al, 1991; Steinberg et 


\section{A Cross-Sectional Design: Marital Satisfaction of Mather and Self-Esteem in Children}

al, 1994) shows that authoritarian, permissive, and neglectful stringent fee has a negative correlation with academic achievement.

\section{STUDY LIMITATIONS}

This study is similar to other studies of people with limitations such that it can be used as follows: 1) the presented study only been used within the students with impaired vision com and 2) lack of control in other factors affecting the efficacy of the limitations of the present study can be outlined.

\section{RESEARCH IMPLICATIONS}

Going on to mention several proposals in order to apply in future studies: 1) It is recommended that efficacy be reviewed in other exceptional groups as well as others , 2) it suggests that selfefficacy be reviewed in college students and other ages 3) is recommended in order to assess the efficacy female sample be used.

\section{Acknowledgments}

The author appreciates all those who participated in the study and helped to facilitate the research process.

\section{Conflict Of Interests}

The author declared no conflict of interests.

\section{REFERENCES}

Bandura, A. (1997). Social cognitive theory of self-regulation. Organizational Behavior and Human Decision Processes, 50, 248-287.

Dornbusch, S.M., Ritter, P. L., Leiderman, R. H., Roberts, D. F., \& fraleigh, M. Y. (1987). The relation of parenting style to adolescent school performance. Child development,58, 1294-1254.

Hind, A.M. Hammouri .(2004). Attitudinal and motivational Variables related to mathematics achievements in Jordan. Educational Research, 46, 3

Karademas, E.(2007). "Positive and negative aspects of well-being: Common and specific predictors”. Personality and Individual Differences , 43, 277- 287.

Lajevardi Z.(1992). [Comparison of depressed mothers can teach mentally retarded children and normal children]. M.Sc. Dissertation. Tehran: Tehran University. 11-26. (Persian)

Lamborn, S. D., Mants, N. S., Steinberg, L., \& Dornbusch, S. M. (1991). Patterns of competence and adjustment among adolescents form authoritative, authoritarian, indulgent, and neglectful families. Child Development, 62, 1049-1056.

M Saket (2016) Content Analysis of the Civics Textbook in Iran and Providing a Theoretical Framework for the Appropriate Criteria of Determining Content according to the Teachers and Authors' View , International Journal of Indian Psychology, Volume 3, Issue 3, No.5, DIP: 18.01.092/20160303, ISBN: 978-1-365-11117-4 
McConkey, Rxz., Truesdale-Kennedy, M., Chang, M., Jarrah, S., and Shukri, R. (2007). “The impact on mothers of bringing up a child with intellectual disabilities: A cross-cultural study”. International Journal of Nursing Studies (in press) Published Online October 2006

Michaeli, F. Structural relationships between psychological well-being and emotional intelligence perceived ability to control depression in mothers of children with disabilities and comparing them negatively with the normal Madera Research on Exceptional Children, 2009, Vol.9, No. 2, 103-120

Mohammadi M, Dadkhah B.( 2001). [Psychological and social problems compared to parents of mentally retarded children under the Welfare of Ardebil]. Journal of Rafsanjan University of Medical Sciences; 1(3): 206-20. (Persian)

Narimani M, Aqamohammadian H, Rajabi S.(2007). [Mental health compared to children with exceptional mental health of mothers of normal children]. Journal of fundamentals of mental health;9(1-2):15-24. (Persian)

Olsson, M. B., \& Hwang, C. P. (2001). "Depression in mothers and fathers of children with intellectual disability”, Journal of Intellectual Disability Research, 45, 535-545.

How to cite this article: M Saket (2016), A Cross-Sectional Design: Marital Satisfaction of Mather and Self-Esteem in Children, International Journal of Indian Psychology, Volume 3, Issue 3, No. 7, DIP: 18.01.123/20160303, ISBN: 978-1-365-12175-3 